\title{
REVIEW
}

\section{Current aspects of fish vaccination}

\author{
A. E. Ellis \\ Department of Agriculture and Fisheries for Scotland, Marine Laboratory, Victoria Road, Aberdeen AB9 8DB, Scotland
}

\begin{abstract}
Although only 3 (bacterial) vaccines are commercially available at present for use in aquaculture, the development of at least 5 other bacterial vaccines and 5 viral vaccines is being actively investigated. Some current aspects of this research are reviewed, in particular: (a) the need to differentiate protection based on short-term non-specific defence responses (induced by certain components of vaccines including LPS and adjuvants) and long-term specific immune memory; (b) the need to identify protective antigens in order to optimize their production in vitro; (c) the possibility, in appropriate circumstances, of using immunopotentiators as prophylactic adjuncts to immunisation.
\end{abstract}

\section{INTRODUCTION}

Since the first commercially licensed vaccines for fish became available (against enteric-redmouth, ERM, in 1976, followed shortly afterwards by a vibriosis vaccine) there has been a great deal of research to produce vaccines against other important fish diseases. However, the ERM and vibriosis vaccines are still the only highly effective commercial vaccines available. Several companies market a furunculosis vaccine but while the protection it affords is by no means high, the companies argue that, following outbreaks of furunculosis, about $10 \%$ more vaccinated fish will reach market size which economically justifies its use. It is a widely held belief that the furunculosis vaccines do not act by stimulating a protective specific immune response but in some way stimulate non-specific defence mechanisms.

In eastern Europe, particularly Czechoslovakia, a vaccine against Spring Viraemia of Carp (SVC) is widely used in commercial carp farms. The composition of the vaccine is uncertain but is based on 2 inactivated strains of SVC virus in an oil emulsion and is administered by intraperitoneal (i.p.) injection. Although it is widely used its efficacy has not been well assessed and its mechanism of action little studied (Fijan 1988).

Cold water vibriosis, caused by the bacterium Vibrio salmonicida, is a very important disease of Atlantic salmon Salmo salar in Norway. Rapid progress has been made in developing an immersion vaccine (a formalin-inactivated whole bacterial culture), which has undergone successful field trials (Holm \& Jorgensen 1987). However, it appears that high levels of protection are achieved only after fish are vaccinated on 2 occasions separated by several weeks.

Experimental vaccines against most other important economic diseases of cultured fish are currently being tested. While some of these vaccines have achieved a satisfactory degree of protection in laboratory trials most of them suffer from problems relating to expense of production, convenience of administration, safety or, most importantly, inadequate potency. The diseases against which there is work in progress to develop vaccines is shown in Table 1. Details on their nature, effectiveness and usefulness in commercial aquaculture are given in Ellis (1988).

At the moment, the efforts of most research workers in the field are directed to 'protecting' fish against important diseases but many published results, which appear to give an optimistic impression on the value of experimental 'vaccines', may be misleading. This is because of inadequate knowledge of the protective responses and inadequate procedures for testing experimental vaccines. In other words, the question as to whether protection is based on specific or nonspecific defence mechanisms must be answered. Undoubtedly, non-specific mechanisms play an important role in protection, and improved means of enhanc- 
Table 1. Fish diseases or their causative agents against which the development of vaccines is currently in progress

\begin{tabular}{|ll} 
Bacterial diseases & Aeromonas hydrophila \\
& Bacterial Kidney Disease (Renibac- \\
& terium salmoninarum) \\
& Edwardsiella tarda \\
& Edwardsiella ictaluri \\
& Vibrio salmonicida (cold water vib- \\
& rosis) \\
Viral diseases & Infectious Pancreatic Necrosis (IPN) \\
& Viral Haermorrhagic Septicaemia \\
& (VHS) \\
& Infectious Haematopoietic Necrosis \\
& (IHN) \\
& Channel Catfish Virus \\
& Spring Viraemia of Carp (SVC) \\
& Ichthyophthiriasis \\
Parasites & Costiasis \\
& Trypanosomiasis \\
& Diplostosomiasis \\
& Vibriosis \\
Commercially & Enteric redmouth (ERM) \\
available vaccines & Furunculosis
\end{tabular}

ing these responses by adjuvants or immunopotentiators may well provide an alternative form of treatment to vaccines. Thus, there are 2 aspects of vaccination which are central to the development of further effective vaccines. These are: (1) identification of the protective response and protective antigens, and (2) the effects and use of adjuvants and immunopotentiators.

This article will concentrate on these aspects.

\section{NATURE OF PROTECTION}

The aim of vaccination is to induce long-term immunity by stimulating the anamnestic (memory) component of the specific immune response. It is this aspect of the specific immune response which is absent from non-specific defence responses and which vaccination attempts to exploit. Unfortunately, most of the published data on experimental vaccines relate to trials which test neither specificity nor memory. Typically, trials involve challenging fish 4 to $8 \mathrm{wk}$ post-vaccination but only with the pathogen vaccinated against. It would be more informative in a short-term test if a control group of vaccinated fish, challenged with an unrelated pathogen, were included in order to test specificity of the protection. On the other hand, if longterm protection can be assessed it would not be so important to test specificity

The importance of testing specificity of protection, with the implication that if protection is specific there will be a memory component, is that protection in the short term may be due to non-specific defence factors. This is particularly the case for bacterial vaccines, where protection may result from non-specific effects of adjuvants or lipopolysaccharide, and for live viral vaccines where protection may be due to viral interference mechanisms. In neither case is protection likely to be long lived.

\section{Non-specific adjuvant efiects}

Many experimental vaccines are injected in Freund's Complete Adjuvant (FCA) which in mammals is known to result in the release of interleukins such as granulocyte/macrophage colony stimulating factors (CSE) and migration inhibition factor (MIF) (Cohen et al. 1979) which in turn result in the non-specific activation of macrophages. A similar effect in fish may be important in defence against furunculosis. Olivier et al. (1985) found that i.p. injection of (modified) FCA (but not glycogen) elicited macrophages which were able to kill virulent Aeromonas salmonicida cells. Furthermore, the $\mathrm{LD}_{50}$ for $A$. salmonicida in fish injected with FCA was increased 400 - to 500 -fold.

\section{Non-specific bacterial effects}

Most bacterial pathogens of fish are Gram-negative and contain lipopolysaccharide (LPS) as a component of their outer membranes. In mammals, LPS can, through a complex system involving interleukins, result in nonspecific lymphocyte and macrophage activation (Cohen et al. 1979). Both effects are also known in fish. LPS has mitogenic activity for fish lymphocytes (Warr \& Simon 1983) and increases phagocytic rates (MacArthur \& Fletcher 1985). Killed Aeromonas salmonicida cells are capable of activating macrophages in rainbow trout Salmo gaidneri when injected i.p. in Freund's Incomplete Adjuvant (FIA). Peritoneal exudate macrophages showed increased $\mathrm{O}_{2}^{-}$and $\mathrm{H}_{2} \mathrm{O}_{2}$ production, RNA synthesis, phosphatase activity and bactericidal activity as compared with macrophages elicited by FIA alone (Chung \& Secombes 1987).

\section{Viral interference mechanisms}

While virus-neutralising antibody is indisputably involved in protection against viral haemorrhagic septicaemia (VHS) (de Kinkelin 1988), attenuated live VHSV vaccines may stimulate other mechanisms of protection. As early as $24 \mathrm{~h}$ post-vaccination, fish held at $11^{\circ} \mathrm{C}$ exhibit high levels of protection. This is 
thought to be due to interferon production which is rapid above $10^{\circ} \mathrm{C}$ (de Kinkelin 1988).

In other studies with an attenuated VHS virus (Reva virus), Vestergaard-Jørgensen (1982) found a complex interaction of factors determining the mode of protection. The data from these experiments are summarized in Table 2 .

The best protection was achieved when fish were held at $5^{\circ} \mathrm{C}$ and this was associated with long-term persistence of the Reva virus. At 10 to $20^{\circ} \mathrm{C}$ interferon production in trout is rapid and may account for the rapid disappearance of the Reva virus at these temperatures. Curiously, at $20^{\circ} \mathrm{C}$ the neutralising antibody titres were lower than at $5^{\circ} \mathrm{C}$. This is probably due to the rapid elimination of the Reva virus by high interferon production, thus reducing stimulation of the antibody response.

Thus, in this instance, protection against VHS appears to be based on at least 2 mechanisms: interferon and antibody production. These mechanisms are interacting and dependent on temperature with the optimum immune protection being achieved at low temperatures $\left(5\right.$ to $\left.10^{\circ} \mathrm{C}\right)$.

\section{Improving vaccines}

In order to characterize immune protection (and to improve it), 2 essential components of vaccination must be identified: the protective antigen(s) and the protective response (cell-mediated immunity [CMI] and/or antibody). In no instance of vaccines used for fish are both these factors known.

The protective antigen in Vibrio vaccines is the LPS (Evelyn 1984) though the actual epitopes are still unknown. As the structure of LPS molecules can vary between strains it is important for quality control of vaccine production that these epitopes be identified. It is also known that protection can be due to specific antibodies since passive immunisation of fish with immune serum confers protection (Harrell et al. 1975). Absorption of agglutinating activity from the serum by $V$. anguillarum cells removed the protective ability and the degree of protection over time correlated with the levels of agglutinating antibody remaining in the circulation of passively immunized fish. However, correlation between protection and presence of serum antibodies in immersion vaccinated fish is not always seen (Croy \& Amend 1977). Others have correlated protection with antibodies in skin mucus rather than serum (Kawai et al. 1981).

The protective antigen of ERM vaccines also appears to be LPS (Amend et al. 1983). In a recent study, protection was not found to be correlated with serum agglutinating antibody levels and it was considered to be mediated by mechanisms other than antibody (Cossarini-Dunier 1986). Such conclusions should be made cautiously, for several reasons. Protection may be due to secretory rather than serum antibody; agglutinating assays are probably a measure of many different antibodies to many different antigenic epitopes on the bacterial surface, and not all antibodies to these epitopes may be protective; the protective antibodies may not cause agglutination, i.e. the assay is irrelevant. Furthermore, the level of antibody existing prior to challenge may be irrelevant; the number of memory cells is more important as they determine the strength of the secondary response induced by the challenge.

One means of determining if protection is associated with the humoral response is by passive immunisation with immune serum. Furthermore, by using antibodies specific to known purified antigens it is possible to identify the protective antigen. This approach is being used to identify the protective antigens against furunculosis and VHS.

Studies using 2 rabbit antisera to Aeromonas salmonicida extracellular products which differed principally only in the presence of antibodies to the extracellular protease indicate that the latter is an important protective antigen against furunculosis (Ellis et al. 1988). In the case of VHS, passive immunisation of trout with mouse monoclonal antibodies to each of the 6 VHSV antigens has shown the membrane glycoprotein ( $\mathrm{G}$ protein) to be the protective antigen (Lorenzen et al. 1987). This work further demonstrated the

Table 2. Salmo gairdner. Effectiveness of vaccination with Reva virus (after Vestergaard-Jørgensen 1982)

\begin{tabular}{|c|c|c|c|c|c|}
\hline Vaccination & Held at & Challenge & Survival \% & Reva persistence & $\begin{array}{c}\text { Neutralising } \\
\text { antibody (Week 12) }\end{array}$ \\
\hline $10^{\circ} \mathrm{C}$ for $5 \mathrm{~d}$ & $\begin{array}{l}5^{\circ} \mathrm{C} \\
10^{\circ} \mathrm{C} \\
15^{\circ} \mathrm{C} \\
20^{\circ} \mathrm{C}\end{array}$ & $\begin{array}{c}\text { Week } 9 \\
10^{\circ} \mathrm{C}\end{array}$ & $\begin{array}{l}75 \\
40 \\
40 \\
20 \\
\text { Controls } 0\end{array}$ & $\begin{array}{l}>14 \mathrm{wk} \\
<1 \mathrm{wk} \\
<1 \mathrm{wk}\end{array}$ & $40-160$ \\
\hline
\end{tabular}


difficulty in devising an in vitro test of protection. Two monoclonal antibodies specific for different epitopes on the $\mathrm{G}$ protein provided equal protection in passively immunized fish yet only one neutralized the VHSV in vitro. In this case, therefore, protection may not necessarily correlate with in vitro virus neutralization.

Having identified the protective antigen by passive immunization there are 3 subsequent steps necessary to develop an effective vaccine. Firstly, to establish the immunogenicity of the antigen in the host species. It is possible that, as an adaptation to surviving in vivo, the protective antigens are poorly immunogenic in the natural host. This seems to be the case with many of the Aeromonas salmonicida antigens, including the protease (Hastings \& Ellis 1988). In such cases it is necessary to determine means of improving the immunogenicity in the host by chemically or physically modifying the antigen but without destroying its antigenicity. Secondly, practical methods of administering the antigen must be developed to obtain a sufficiently strong immune response to provide protection. And thirdly, the antigen must be capable of being produced cheaply. This might be done by cloning the DNA coding for the protective antigen in a bacterium to massproduce the antigen. The research investment for this may be expensive but once the clone is established, mass production of the antigen would be cheap and simple.

\section{USE OF IMMUNOPOTENTIATORS AND ADJUVANTS}

An immunopotentiator is an agent which augments the immune response in a very general sense. Adjuvants are immunopotentiators but the term is used only for those agents which enhance the specific immune response (CMI and antibody response) as well as non-specific defence responses. There are 2 reasons for using these agents in aquaculture: (1) as a means of enhancing the immune response to a vaccine; (2) as stimulators of non-specific defence mechanisms which could provide increased protection against a wide range of pathogens.

\section{Enhancing specific immunity}

Most adjuvants have been developed for injection administration which is inconvenient for mass vaccination of fish. Furthermore, many adjuvants have undesirable side effects, e.g. FCA, FIA, and potassium aluminium sulphate can cause visceral adhesions, peritonitis, tissue liquifaction and mortalities (Home et al. 1984). Commercial use of many adjuvants may therefore be limited. Safer adjuvants, used in veterinary medicine, include aluminium hydroxide gel (sometimes mixed with saponin as in the Foot and Mouth Disease vaccine) and certain oil emulsions of confidential composition used in Newcastle Disease vaccine for poultry. These 2 adjuvants have been tested in rainbow trout Salmo gairdneri and while enhancement of antibody production was achieved they were not as effective as FCA (Cossarini-Dunier 1985) Another adjuvant without side effects is ETE (Ecteinascidia turbinata extract) which enhanced antibody production in eels when injected $2 \mathrm{~d}$ after the antigen (McCumber et al. 1981).

The most useful adjuvants in aquaculture are those which could be combined with immersion or oral vaccines. To date only a few have been tested and only with a limited number of antigens or vaccines. These include:

(1) Potassium aluminium sulphate, when combined with Vibrio immersion vaccine, led to increased antigen in uptake (Tatner \& Horne 1983). Improved efficacy of oral Vibrio vaccines in combination with this adjuvant has been reported (Agius et al. 1983).

(2) DMSO (dimethyl sulphoxide) increased antibody production in rainbow trout when combined with ERM immersion vaccine (Anderson et al. 1984)

(3) BCG (Bacillus Calmette-Guérin) and Quilaja saponin with ERM immersion vaccine did not enhance the antibody response or serum killing but bacterial clearance was improved (Grayson et al. 1987).

(4) FK-565, an immunoactive peptide, enhanced antibody production to Yersinia ruckeri and Aeromonas salmonicida when injected with bacterins into salmonids (Kitao et al. 1987)

\section{Enhancement of non-specific disease resistance}

As with adjuvants, agents which enhance general immunity are mainly administered by injection and the author is not aware of any definitive studies of immunopotentiators administered by immersion or orally other than the immunopotentiating effect of BCG and Quilaja saponin upon clearance of Yersinia ruckeri in rainbow trout referred to above. All other reports are based on injection administration.

The non-specific enhancement of disease resistance by FCA (Olivier et al. 1985) has already been referred to. In the same study, tests were done on MDP (muramyl dipeptide, the water-soluble adjuvant component of Mycobacterial and Levamisole. MDP in saline was ineffective but MDP in oil and levamisole did enhance resistance to furunculosis and vibriosis.

Injection of ETE in eels enhanced non-specific resistance to Aeromonas hydrophila (McCumber et al. 1981). 
FK-565 increased non-specific resistance of rainbow trout to furunculosis when injected $1 \mathrm{~d}$ before challenge but the effect was diminished when injected $3 \mathrm{~d}$ before (Kitao \& Yoshida 1986). The mode of action appears to be based upon activation of macrophages and its immunopotentiating activity was still apparent in fish immunosuppressed by injection of cyclophosphamide.

\section{CONCLUSIONS}

The protection afforded by many experimental vaccines for fish may be due to activation of non-specific defence factors and the protection is likely to be of short duration. Vaccination has practical value only when immune memory of the specific immune response is induced but few studies on experimental vaccines have assessed the induction of immune memory. Specificity of protection and duration of immune memory are important areas for future work.

Adjuvants play a very important role in the efficacy of vaccines by enhancing the immune response. This is vitally important when the protective antigens may by themselves have low immunogenicity or if they are expensive to produce allowing vaccination to be effective with smaller doses. Further work is required to test more adjuvants with more experimental vaccines and especially in combination with immersion and oral vaccines.

Adjuvants and immunopotentiators may be useful by themselves in stimulating non-specific defence mechanisms. The problem here is that duration of the effect is likely to be short. The only long-term study to determine duration of immunopotentiation is the effect of FCA injection on furunculosis resistance which lasted for at least $90 \mathrm{~d}$ (Olivier et al. 1985). However, this is likely to be due to the persistent nature of the mineral-oil component of FCA and agents which are rapidly cleared from the body are unlikely to have durable effects. Nevertheless, even short-term immunopotentiation by an easily administered agent may find use in treating populations of fish at high risk from disease over short periods (e.g. newly transferred smolts to seawater), or as an adjunct of chemotherapy in treatment of infected populations. The rapid effects of FK-565 could be useful here. One area uninvestigated in fish is induction of interferon production. This class of interleukins can be induced in mammals by a bewildering array of agents such as viruses, doublestranded DNA, double-stranded synthetic polynucleotides (e.g. poly I: poly C), microbial products (e.g. LPS), polymeric chemicals (e.g. polycarboxylic polymers, polysulphates) and a large group of small molecular weight compounds including cycloheximide, kanamycin, certain quinolone derivatives, basic dyes (e.g. toluidene and methylene blue, acridine orange) and actinomycin D (Epstein 1979). The rapidity with which fish held at suitable temperatures can produce interferon may make an effective inducer of its production a valuable means of limiting the effects of viral diseases.

Further work is needed to test the duration and breadth of protection induced by administering immunopotentiators to fish. If agents could be found which could be practically administered and which provided relatively long-term resistance without undesirable side effects, they may eliminate the need for vaccines which are expensive to produce commercially.

\section{LITERATURE CITED}

Agius, C., Horne, M. T., Ward, P. D. (1983). Immunisation of rainbow trout, Salmo gairdneri Richardson, against vibriosis: comparison of an extract antigen with whole cell bacterins by oral and intraperitoneal routes. J. Fish Dis, 6 : $129-134$

Amend, D. F., Johnson, K. A., Croy, T R., McCarthy, D. H. (1983). Some factors affecting the potency of Yersinia ruckeri bacterins. J. Fish Dis. 6: 337-344

Anderson, D. P., van Muiswinkel, W B., Roberson, B. S (1984). Effects of chemically induced immune modulation on infectious diseases of fish. In: Kende, M., Gainer, J., Chirigos, M. (eds.) Chemical regulation of immunity in veterinary medicine. A. L. Liss, New York, p. 182-211

Chung, S., Secombes, C. J. (1987). Activation of rainbow trout macrophages. J. Fish Biol. 31 (Suppl. A): 51-56

Cohen, S., Pick, E., Oppenheim, J. J. (eds.) (1979) The biology of the lymphokines. Academic Press, New York

Cossarini-Dunier, M. (1985). Effect of different adjuvants on the humoral immune response of rainbow trout. Dev. Comp. Immunol. 9: 141-146

Cossarini-Dunier, M. (1986). Protection against enteric redmouth disease in rainbow trout, Salmo gairdneri Richardson, after vaccination with Yersinia ruckeri bacterin. J. Fish Dis. 9: 27-33

Croy, T R., Amend, D. F. (1977). Immunisation of sockeye salmon (Oncorhynchus nerka) against vibriosis using the hyperosmotic infiltration technique. Aquaculture 12: $317-325$

Ellis, A. E. (1988). (ed.) Fish vaccination. Academic Press, London

Ellis, A. E., Burrows, A. S., Hastings, T S., Stapleton, K. J. (1988). Identification of Aeromonas salmonicida extracellular protease as a protective antigen against furunculosis by passive immunisation. Aquaculture (in press)

Epstein, L. B. (1979). The comparative biology of immune and classical interferons. In: Cohen, S., Pick, E., Oppenheim, J. J. (eds.) Biology of the lymphokines. Academic Press, New York, p. 443-514

Evelyn, T. P. T (1984). Immunisation against pathogenic vibriosis. In: de Kinkelin, P. (ed) Symposium on fish vaccination. O.I.E., Paris, p. 121-150

Fijan, N. (1988). The status of vaccines against spring viraemia of carp. In: Ellis, A. E. (ed.) Fish vaccination. Academic Press, London (in press) 
Grayson, T. H., Williams, R. J., Wrathmell, A. B., Munn, C. B., Harris, J. E. (1987). Effects of immunopotentiating agents in the immune response of rainbow trout, Salmo gairdneri Richardson, to ERM vaccine. J. Fish Biul. 31 (Suppl. A): 195-202

Harrell, L. W., Etlinger, H. M., Hodgins, H. O. (1975). Hurnoral factors important in resistance of salmonid fish to bacterial diseases. I. Serum antibody protection of rainbow trout (Salmo gairdneri) against vibriosis. Aquaculture 6: 211-220

Hastings, T S., Ellis, A. E. (1988). The humoral immune response of rainbow trout and rabbits to extracellular products of the fish pathogen Aeromonas salmonicida. J. Fish Dis. (in press)

Holm, K. O., Jorgensen, T (1987). A successful vaccination of Atlantic salmon, Salmo salar L. against 'Hitra disease' or cold water vibriosis. J. Fish Dis. 10: 85-90

Horne, M. T., Roberts, R. J., Tatner, M. F., Ward, P. (1984). The effects of the use of potassium alum adjuvant in vaccines against vibriosis in rainhow trout, Salmo gairdneri Richardson. J. Fish Dis. 7: 91-99

Kawai, K., Kusuda, R., Itami, T. (1981). Mechanisms of protection in ayu orally vaccinated for vibriosis. Fish Pathol. 15: $257-262$

Kitao, T., Yoshida, Y. (1986). Effect of an immunopotentiator on Aeromonas salmonicida infection in rainbow trout (Salmo gairdneri). Vet. Immunol. Immunopathol. 12: 287-296

Kitao, T., Yoshida, T, Anderson, D. P., Dixon, O. W., Blanch, A. (1987). Immunostimulation of antibody-producing cells and humoral antibody to fish bacterins by a biological response modifier. J. Fish Biol. 31 (Suppl. A) : 87-91
Kinkelin, de P. (1988). Vaccination against viral haemorrhagic septicaemia. In: Ellis, A. E. (ed.) Fish vaccination. Academic Press, London (in press)

Lorenzen, N., Vestergard Jørgensen, P., Oleson, N. J. (1987). Passive protection of rainbow trout (Salmo gairdneri) against Egtved virus with monoclonal antibodies. Abstracts of Fish Immunology Symposium, Plymouth Polytechnic, Plymouth, UK

MacArthur, J. L., Fletcher, T. C. (1985). Phagocytosis in fish. In: Manning, M. J., Tatner, M. F. (eds.) Fish immunology. Academic Press, London, p. 29-46

McCumber, L. J., Tranger, R., Siegel, M. M. (1981). Modification of the immune system of the American eel, Anguilla rostrata by ETE. Develop. Biol. Standard. 49: 289-294

Olivier, G., Evelyn, T. P. T., Lallier, R. (1985). Immunity to Aeromonas salmonicida in coho salmon (Oncorhynchus kisutch) induced by modified Freund's complete adjuvant: its non-specific nature and the probable role of macrophages in the phenumenon. Dev. Comp. Immunol. 9: $419-432$

Tatner, M. F., Horne, H. T (1983). Factors influencing the uptake of ${ }^{14} \mathrm{C}$-labelled Vibrio anguillarum vaccine in direct immersion experiments with rainbow trout, Salmo gairdneri Richardson. J. Fish Biol. 22: 585-591

Vestergard-Jørgensen, P. (1982). Egtved-virus: temperature dependent immune response of trout to infection with low virulence virus. J. Fish Dis. 5: 47-56

Warr, G. W. Simon, R. C. (1983). The mitogen response potential of lymphocytes of the rainbow trout (Salmo gairdneri) re-examined. Dev. Comp. Immunol. 7: 379-384 